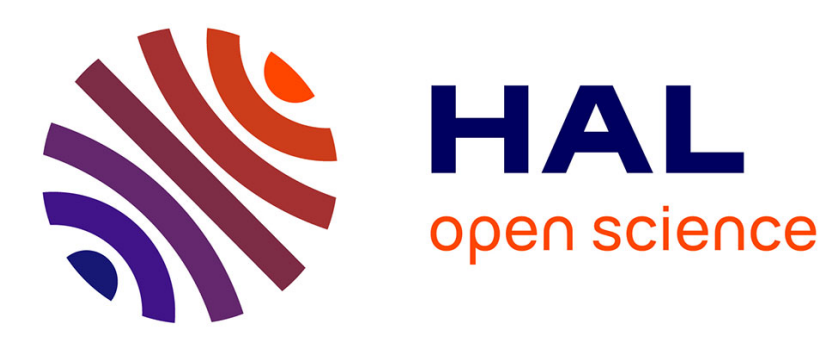

\title{
On the Impact of Product Usability on CT Scan Scheduling: The Case of Saudi Hospitals
}

Saad Aldoihi, Omar Hammami

\section{To cite this version:}

Saad Aldoihi, Omar Hammami. On the Impact of Product Usability on CT Scan Scheduling: The Case of Saudi Hospitals. International Conference on Computer Applications \& Information Security (ICCAIS), May 2019, Riyadh, Saudi Arabia. hal-02191138

\section{HAL Id: hal-02191138 \\ https://hal.science/hal-02191138}

Submitted on 23 Jul 2019

HAL is a multi-disciplinary open access archive for the deposit and dissemination of scientific research documents, whether they are published or not. The documents may come from teaching and research institutions in France or abroad, or from public or private research centers.
L'archive ouverte pluridisciplinaire HAL, est destinée au dépôt et à la diffusion de documents scientifiques de niveau recherche, publiés ou non, émanant des établissements d'enseignement et de recherche français ou étrangers, des laboratoires publics ou privés. 


\section{On the Impact of Product Usability on CT Scan Scheduling: The Case of Saudi Hospitals}

\author{
Saad Aldoihi \\ Computer Science and Systems Engineering \\ ENSTA ParisTech \\ Palaiseau Cedex, France \\ aldoihi@ensta.fr
}

\author{
Omar Hammami \\ U2IS \\ ENSTA ParisTech \\ Palaiseau Cedex, France \\ Hammami@ensta.fr
}

\begin{abstract}
Product usability has been subjected to many evaluation techniques. Many evaluation techniques use heuristics approach to evaluate the overall usability of the product. Considering heuristics works in some particular examples, In the healthcare sector, heuristics approach is hard to implement due to fundamental constraints (stakeholders, safety, and time requirements). This paper examines a scheduling algorithm that correlates to usability problem. The scheduling algorithm has a definite impact on the product Return of investment and customer satisfaction.

Index Terms-CT Scan scheduling, CT Scan operational Usability
\end{abstract}

\section{PURPOSE/AIM AND BACKGROUND}

CT scan is sensitive to demographical factors. (Aldoihi, Hammami, 2018) found that CT scan usability attributes are indeed differed based on a demographic characteristic such as gender and years of experience. Many CT technicians are still troubled with CT's usability due to its complexity and interconnectivity with other ecosystems (Aldoihi, Hamammi, 2018). One key contributing factor is invisible physical and mental exertion generates while operating a CT scan. (Aldoihi, Hammami, 2019) found mounting evidence that there is an extremely high amount of physical and mental exertions during daily CT operations. Product usability is extremely interconnected with a different operational and organizational ecosystem where the interconnectivity transferred into exertions on the operator. Thus, product usability will have an impact on the operator in term of bonding to its many requirements (such as safety, optimization, and scheduling). Scheduling tasks in hospitals have been the subject of numerous studies and we aim at analyzing in the state of the art of scheduling with the use of product usability and the resulting time uncertainty.

\section{CT SCAN PRODUCT USABILITY FINDINGS}

CT scan is an extremely complicated machine. It takes many years of training to master its basic functionality, and it required the involvement of technician, patient, and the machine to maneuver only one task. More importantly, $\mathrm{Ct}$ scan is indispensable evaluation tool. It evaluates the patient's internal organs for various conditions. More significantly, such evaluations enable doctors to visualize an instant image of the affected organs, and eventually, doctors are able to take accurate decision based on the severity. Usability is a decisive element of the CT scan. In a study of evaluating the usability of CT scan, (Aldoihi, Hammami, 2018a) found there is 67 usability Catastrophe that can lead to death or major injury while operating CT scan. Additionally, there are 181 major usability, 193 minor usability, and 88 cosmetic problems. These usability issues in total are 529. (Aldoihi, Hammami, 2018b) evaluated CT scan usability based on 14 attributes, and they found Memory (scored $27 \%$ on the catastrophic scale), Visibility (scored $20 \%$ on the catastrophic scale), Consistency, (scored $18 \%$ on the catastrophic scale), and Flexibility (scored $18 \%$ on the catastrophic scale) are most complaint about by CT scan Technicians. Besides usability, exertions are fundamentally essential factors. (Aldoihi, Hammami, 2018b) found technicians' mental exertion at its maximum (23\%) while operation CT scan. In essence, exertions go hand in hand with usability. (Aldoihi, Hammami, 2019) observed some CT scan routine operational practice transformed into exertions. They called it an invisible exertion where action like transferring the bedridden patient from hospital bed onto CT scan's table result in tremendous physical exertions adds-up. (Aldoihi, Hammami, 2019) divided exertions into two parts which are physical and mental. Each part consists of three statements. For the physical exertion, $80 \%$ of the radiologist confirmed that they regularly transfer a bedridden patient to CT scan's table. Similarly, 93\% of radiologist confirm that they engage in routinely preparing the room for receiving the next patient which include cleaning and disinfecting the CT scan table. A final physical statement, $89 \%$ of radiology confirmed that they frequently administrate the contrast media for all patients. For the mental exertion, $57 \%$ of radiologist believed that they work in an understaffed environment. $70 \%$ of radiologist believed that under current working environment the radiology department needs more CT scan machine. $57 \%$ of radiologist believed that management targets are not aligned with the existing resource.

\section{STATE OF THE ART}

Several studies have addressed the scheduling of personnel and resources in the hospital context. Among others physician scheduling, multi-period and multi-resource operating room scheduling and block scheduling at magnetic resonance imaging labs. The question addressed by this paper is: what type of 
task duration model has been used in tasks scheduling which can take into account product usability impact ? as an example we take the following models of CT Scan tasks execution time over a day with the assumption of 15 mins baseline examination duration and 20 patients processing.

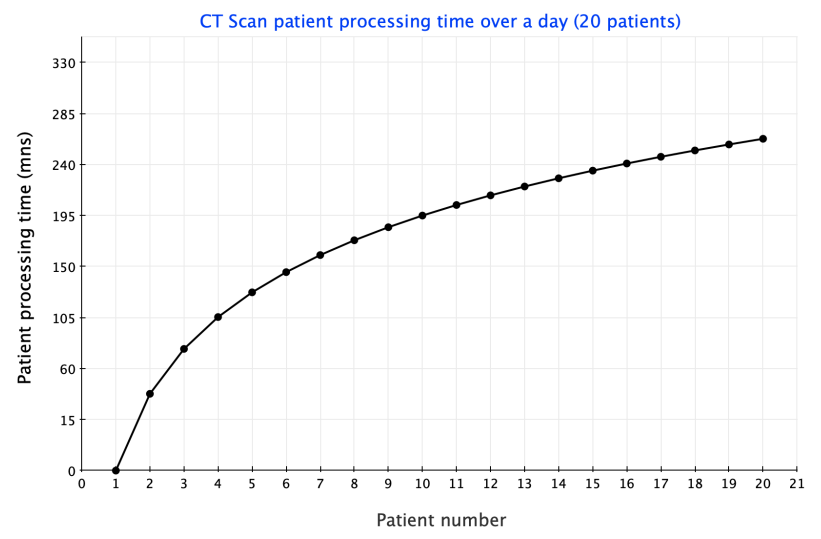

Fig. 1. $\log$ distribution

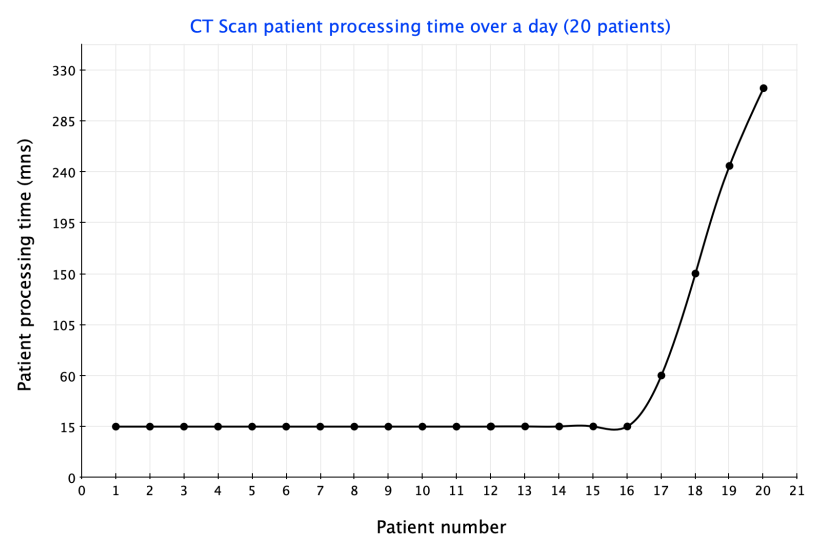

Fig. 2. Exp. distribution

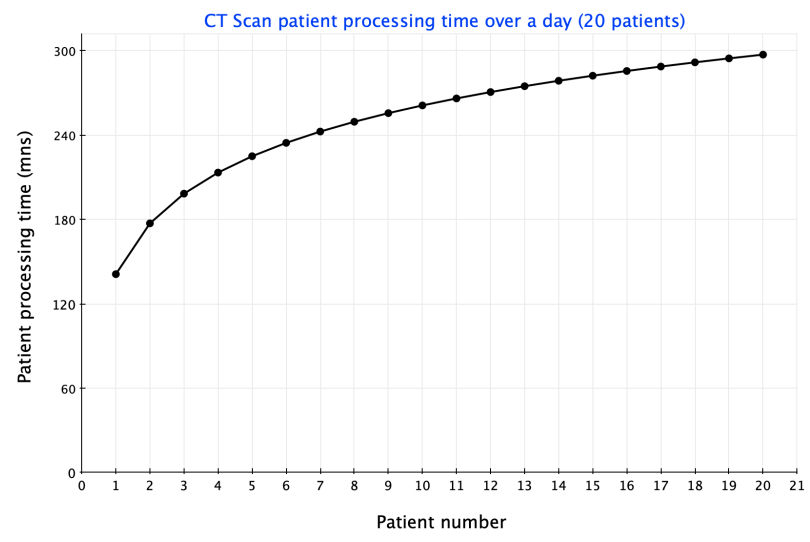

Fig. 3. $\log$ distribution ( $\mathrm{n} 15 \mathrm{mins})$

These 6 cases represent the various impact of product usability with Fig. 5 being the theoretical case where tasks

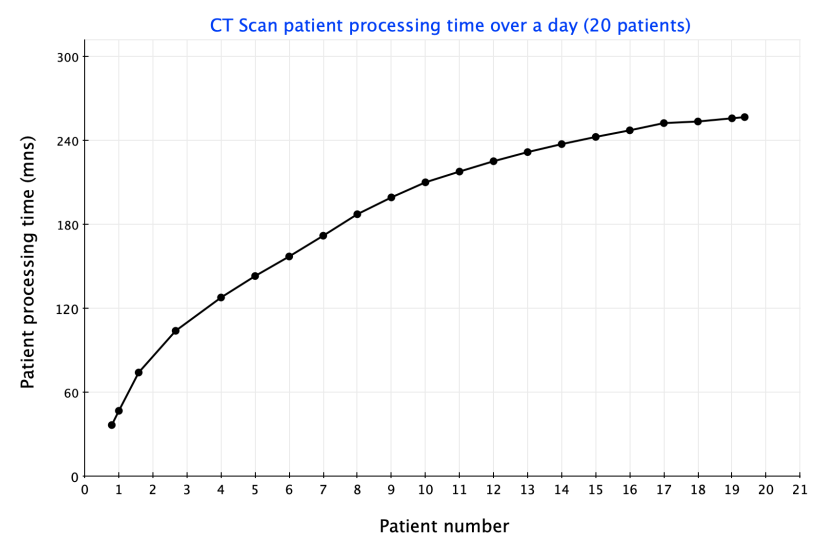

Fig. 4. Exp. distribution (n x 15 mins)

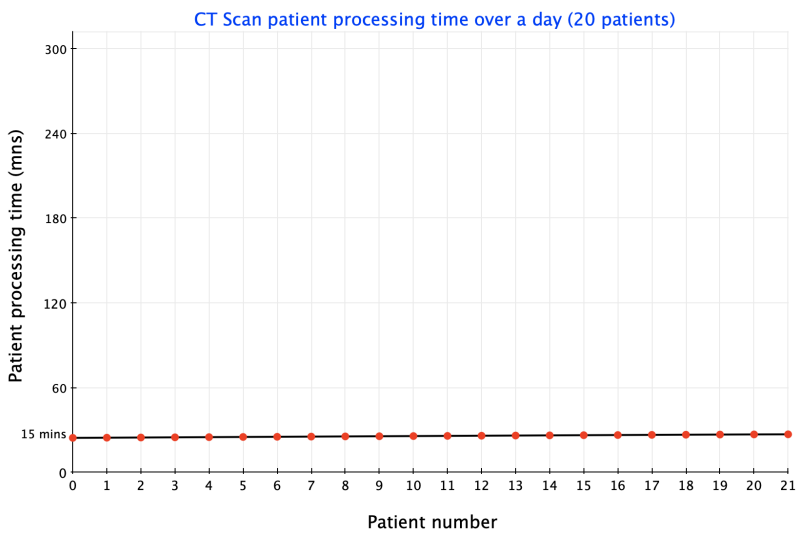

Fig. 5. linear distribution

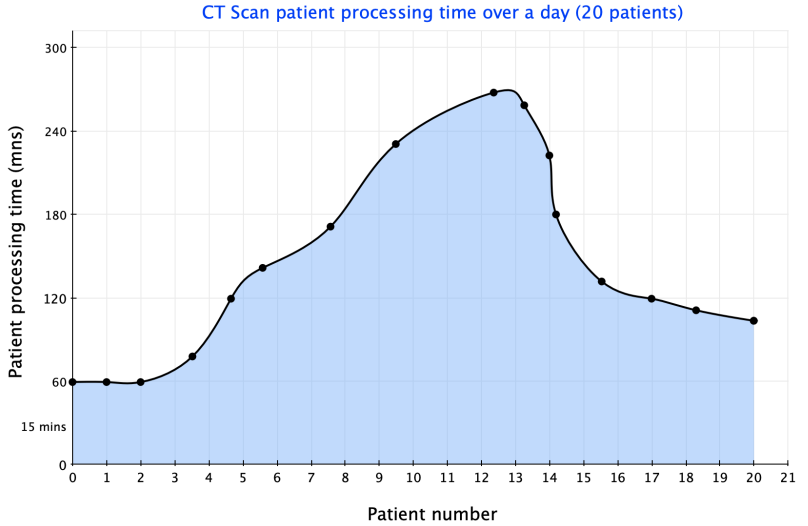

Fig. 6. random distribution 
are conducted with constant duration while the exponential distribution describes the situation where tasks duration grows exponentially over the day with last tasks being the longest reflecting cumulative effects of product usability. The random distribution describes variations during the day (start of the day, end of the morning, after lunch and before the end of the day.

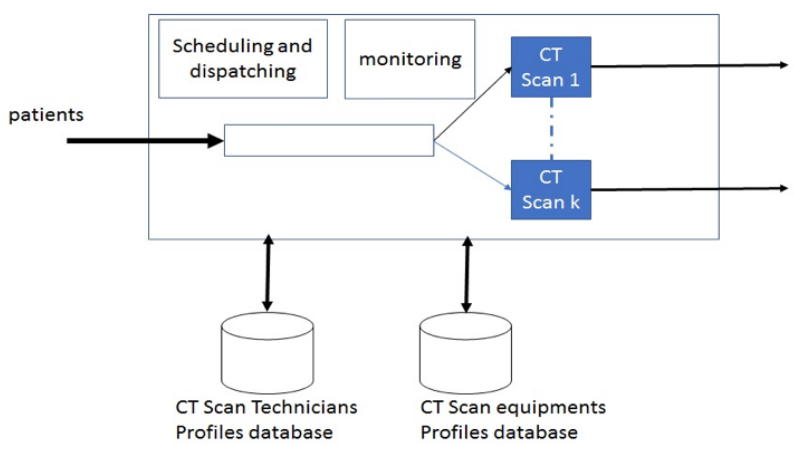

Fig. 7. Product Usability /technician CT Scan Dynamic Scheduling

The assumption here is that task duration per CT scan is collected for each task execution part of the HCI. This monitoring only purpose is to avoid considering artificial tasks duration models or tasks duration distributions and rather take into account the actual durations. The objective being to avoid mental and physical exertion on the technician and better overall scheduling for the hospitals. This data collection can also be accessed by the CT scan technician to better also understand his/her own evolution and condition.

\section{FINDINGS AND RESULTS}

The conducted review of the state of the art in scheduling models proposed in the literature in hospitals context shows that product usability is not taken into account for finetuning tasks execution time. Whatever the technician level of education, work experience, age, gender specificities tasks are assumed constant in CT scan operations. Heterogeneity is absent. The dominant optimization technique used for scheduling being linear programming requires constant task execution time which is not appropriate.

Our findings trigger a new avenue of research balancing the existing results achieved in the literature on the estimation of the required consultation time distribution based on the required type of medical treatment and the person's characteristics like age, medical record and the number of previous visits but from the technician side.

The proposed model of CT Scan scheduling is described in figure 7. Patients arrive in FIFO (First-in First-out) order and are scheduled and dispatched over several CT scan machines based on CT scan technician product usability profiles. The CT scan tasks are monitored and tasks duration are collected for every technician operating CT scan machine over the day building a database of CT Scan technician correlated to a database of CT scan equipment. The scheduling and dispatching unit will apply dynamic scheduling over the CT scan machines exploiting CT scan technician profiles with product usability.

This boils down to scheduling optimization under uncertainty and can be improved in the era of big data and deep learning. The proposal is to integrate machine learning to build predictive models of CT scan technician profiles.

The proposed optimization technique to be used with product usability model per technician being multi-objective evolutionary (NSGA-II).

Future work is to be conducted in collecting data from CT Scan technicians with more data to be collected in hospitals with technician task execution time duration recording.

\section{CONCLUSion}

Product usability studies have large consequences in daily tasks and among them tasks scheduling. It is essential to integrate models of product usability over time in the scheduling of hospitals tasks scheduling for realistic execution of tasks. In the case of the CT scan, we argue that models should be proper to each technician taking into account education level, work experience, age, and several other parameters to allow fine-tuning. Reducing task execution time uncertainty through new predictive models based on product usability will improve return on investment (ROI) for costly CT scan equipment, reduce unnecessary overload and improve hospitals customer satisfaction.

\section{REFERENCES}

[1] Aldoihi, S., and Hammami, O. (2018). Evaluation of CT Scan Usability for Saudi Arabian Users. In Computer, Information and Telecommunication Systems (CITS), 2018 International Conference on (pp. 119-124). IEEE.

[2] Aldoihi, S., and Hammami, O. (2018). User Experience of CT Scan: A Reflection of Usability and Exertions. In Computer Systems and Applications (AICCSA), 2018 IEEE/ACS 15th International Conference

[3] Aldoihi, S., Hammami, O. (2019, April). Evaluation of Invisible Physical and Mental Exertion from CT Scan Operation in Saudi Arabian Hospitals. In 2019 6th International Conference on Control, Decision and Information Technologies (CoDIT).

[4] A. Suleiman,, M.Z. Mahmoud, O. Serhan, B. Alonazia, M. Alkhorayef, K. Alzimami, D. Bradley, CT examination effective doses in Saudi Arabia, Applied Radiation and Isotopes 141 (2018) 261-265

[5] A.Karim Jabalia, Khalid Yousuf Faridb, Abdel-aziz Matanib , Fatma Al Mulhimc Key factors influencing the usage of MRI in Saudi Arabia, International Conference on Communication, Management and Information Technology (ICCMIT 2015)

[6] Abdulaziz Khalid Alotaibi Abdulrahman Alsalim Fahad Alruwaili ; Abdulaziz Almubarak; Albanderi Alhamzah

Abdullah Albahlal ; Malek Alrobaian, Burnout during ophthalmology residency training: A national survey in Saudi Arabia, Saudi Journal of Ophthalmology (2019)

[7] Camila Rodrigues Dias, Marluce Rodrigues Pereira, Andre Pimenta Freire, Qualitative review of usability problems in health information systems for Radiology, Journal of Biomedical Informatics 76 (2017) 1933

[8] Melanie Erhard, Jan Schoenfelder Andreas Fugener, Jens O. Brunner, State of the art in physician scheduling, European Journal of Operational Research 265 (2018) 1-18

[9] Suzanne R. Dhainia,b, Kris Denhaeryncka, Stefanie Bachnicka, Rene Schwendimanna,c, Maria Schuberta,c, Sabina De Geesta, Michael Simona, Work schedule flexibility is associated with emotional exhaustion among registered nurses in Swiss hospitals: A cross-sectional study, International Journal of Nursing Studies 82 (2018) 99-105 
[10] Mohammad Mahdi Vali-Siar, Saiedeh Gholami, Reza Ramezanian, Multi-period and multi- resource operating room scheduling under uncertainty: A case study, Computers and Industrial Engineering 126 (2018) 549-568

[11] Wen-Tso Huanga, Ping-Shun Chen, John J. Liua, Yi-Ru Chenc, YenHsin Chenc, Dynamic configuration scheduling problem for stochastic medical resources, Journal of Biomedical Informatics 80 (2018) 96-105

[12] Anders N. Gullhav, Marielle Christiansen a, Bjørn Nygreen, Mats M. Aarlott, Jon Erik Medhus, Johan Fredrik Skomsvoll , Per Olav Østbyhaug , Block scheduling at magnetic resonance imaging labs, Operations Research for Health Care 18 (2018) 52-64

[13] M. Susana Moreno, Anibal M. Blanco, A fuzzy programming approach for the multi-objective patient appointment scheduling problem under uncertainty in a large hospital, Computers and Industrial Engineering 123 (2018) 33-41

[14] Robert L. Burdett, Erhan Kozan, An integrated approach for scheduling health care activities in a hospital, European Journal of Operational Research 264 (2018) 756-773

[15] Hana Alharthi, Healthcare predictive analytics: An overview with a focus on Saudi Arabia Journal of Infection and Public Health 11 (2018) 749-756

[16] Chao Ning, Fengqi You Optimization under uncertainty in the era of big data and deep learning: When machine learning meets mathematical programming Computers and Chemical Engineering 125 (2019) 434-448 